\title{
Realism and the turn to practice
}

\author{
Rom Harré ${ }^{1,2}$
}

Published online: 28 October 2015

(C) Springer Science+Business Media Dordrecht 2015

These essays spans reach across the spectrum of issues in philosophy of chemistry that runs from reflections on the nature of the knowledge we acquire in chemical research, both on the bench and in the study to the nature of chemical practice. The latter preoccupation intersects with studies of laboratory methods and with the construction of theories and the models of chemical processes on which they rest. Historical episodes thrown light on the central themes of the twenty-first century. The sixteenth and seventeenth centuries are a particularly rich field in which to find examples of attempts at realist metaphysics with which to contrast such studies in the present day. Even then chemistry was very much the practical art that it is predominantly today when most chemists work on the creation of medicaments, industrial and domestic materials and environmental management. The turn to 'practice' leads directly to discussions of moral issues that have become popular recently. The demonstration of the complexity of these issues rounds off this set of papers.

This issue is dedicated to the memory of our greatly valued colleague and friend, Rein Vihalemm who recently died in a boating accident. We will miss his gentle personality and his fruitful insights.

\section{Rom Harré}

harre@georgetown.edu

1 Linacre College, South Parks Road, Oxford OX1 3JA, UK

2 Georgetown University, Washington, DC 20057, USA 